\title{
AMBIGUITY AVERSION IN THE FIELD OF INSURANCE: INSURERS' ATTITUDE TO IMPRECISE AND CONFLICTING PROBABILITY ESTIMATES
}

\begin{abstract}
This article presents the results of a survey designed to test, with economically sophisticated participants, Ellsberg's ambiguity aversion hypothesis, and Smithson's conflict aversion hypothesis. Based on an original sample of 78 professional actuaries (all members of the French Institute of Actuaries), this article provides empirical evidence that ambiguity (i.e. uncertainty about the probability) affect insurers' decision on pricing insurance. It first reveals that premiums are significantly higher for risks when there is ambiguity regarding the probability of the loss. Second, it shows that insurers are sensitive to sources of ambiguity. The participants indeed, charged a higher premium when ambiguity came from conflict and disagreement regarding the probability of the loss than when ambiguity came from imprecision (imprecise forecast about the probability of the loss). This research thus documents the presence of both ambiguity aversion and conflict aversion in the field of insurance, and discuses economic and psychological rationales for the observed behaviours.
\end{abstract}

KEY WORDS: ambiguity aversion, conflict aversion, Ellsberg paradox, insurance.

\section{INTRODUCTION}

Information imprecision and conflict are prevalent in insurance decisions, especially non-life insurance, because experts may not agree on the probability of the risk (e.g. the "mad cow disease", global warming) or because of a lack of large, reliable historical data base (e.g. climatic risks). Since Ellsberg (1961) situations where decision makers do not know the exact likelihoods of each potential event are called "ambiguous" situations. 
The impact of such "uncertainty about the probability" on choices has been well-documented and, contrary to what the normative Subjective Expected Utility framework predicts (Savage, 1954), there is much evidence that ambiguity affects decision-making in some systematic ways: decision makers are usually "averse to ambiguity" especially in the gain domain (e.g. Camerer and Weber, 1992; Lauriola and Levin, 2001). In the loss domain, though ambiguity aversion usually decreases (e.g. Cohen et al. 1985, 1987; Viscusi and Chesson, 1999), numerous studies have also detected ambiguity averse behaviours. In the field of insurance for instance, insurers ask for higher premiums under ambiguity than under risk, and insured persons are willing to pay more to be insured against an ambiguous risk than a "risky" risk (Hogarth and Kunreuther, 1989; Kunreuther et al., 1995).

Several experiments and surveys thus documented the idea that ambiguity matters and significantly affect market prices. However, so far, most of experimental studies have focused on the impact of imprecision ${ }^{1}$ of the probabilities and/or of the outcomes on behaviour (Budescu et al., 2002; Ho et al., 2002; Kunreuther et al., 1995), and few have explored the impact of ambiguity coming from "precise but conflicting" probabilities (Chesson and Viscusi, 2003; Kunreuther et al., 1995; Viscusi and Chesson, 1999). Moreover, when ambiguity has been generated through conflict and disagreement between sources of information, conflicting ambiguity and imprecise ambiguity have been supposed "exchangeable". Actually, apart from Smithson (1999), we do not know any empirical paper which clearly studies the sources of ambiguity (e.g. unreliable probability, conflicting probability, imprecise probability, etc.), and explores the differentiated impacts of different sources of ambiguity on behaviours.

This study elaborates on Smithson's interesting but unexplored distinction and considers that ambiguity can have two different sources: imprecision and conflict. The survey was designed to test empirically whether sophisticated participants, i.e., professional actuaries who are experts in insurance, have a high training in statistics, probability theory and economic 
theory of decision making (e.g. Expected Utility Theory), have preferences between those two different sources of ambiguity, and are more averse to conflicting ambiguity than to imprecise ambiguity. The main hypotheses to be tested were (a) whether insurers do set up higher premiums under ambiguity (hereafter the "ambiguity aversion hypothesis", Ellsberg, 1961), and (b) whether they set up higher premiums when ambiguity comes from conflict and disagreement or from imprecision (hereafter the "conflict aversion hypothesis", Smithson, 1999). In line with Smithson (1999), this article then investigates the concrete consequences of informational preferences for different sources of ambiguity, but it relies on sophisticated participants (instead of students) and looks at concrete business decisions (i.e. insurance decisions).

Furthermore, this study also examines empirically the impact of familiarity and knowledge on attitude towards ambiguity. Indeed, a recent stream of research has emphasised the impact of individual source characteristics, such as the competence, on attitude towards ambiguity, and showed that more knowledgeable people may prefer ambiguous options (Heath and Tversky, 1991). However, so far this "competence hypothesis" has been tested in a very specific experimental design, consisting in choosing between a bet on a general knowledge question and a bet on a game of chance (Fox and Tversky, 1995; Fox and Weber, 2002; Taylor, 1995). An interesting question is then whether the competence hypothesis still holds when participants are asked to price two different options, both characterised by subjective probabilities (e.g. sources of information give their own subjective forecast about the likelihood of an event) but whose degree of ambiguity varies (e.g. precise subjective probability vs. imprecise subjective probability). The article is then also interested in the impact of familiarity on insurers' behaviour, and the third hypothesis tested in this article is a revised version of the competence hypothesis. Finally, this research explores the link between a psychological measure of "intolerance of ambiguity" and the conventional economic measure. Sherman (1974), as well as Gosh and Ray (1992) for instance, found a 
modest correlation between Budner's psychological scale of "Intolerance of Ambiguity" and ambiguity aversion. Table I below summaries the predictions regarding insurers behaviours.

The remainder of the article is organized as follows: Section 2 describes the survey design and Section 3 reports

\section{TABLE I}

Predictions regarding insurers behaviours

P1. Ambiguity aversion

P2. Conflict aversion

P3. Competence or Familiarity effect

P4. Ambiguity aversion and Intolerance of ambiguity
Insurers will set higher premium for a risk with ambiguous probability, whatever the source of ambiguity (i.e. conflict or imprecision) than for a risk with non ambiguous probability.

P2.1. Insurers will set higher premium for an ambiguous risk with a conflicting probability than for an ambiguous risk with a consensual but imprecise probability

$\mathrm{P} 2.2$. Insurers may react more strongly to conflict, and instead of charging higher premium for an ambiguous risk with a conflicting probability, they may reject the insurance demand. Then, insurers will reject more insurance demands in the conflicting condition than in the imprecise condition.

Ambiguity aversion decreases as familiarity increases: insurers who are more familiar with the risks that the scenarios describe, because they usually deal with such risks, will exhibits smaller ambiguity aversion.

Economic measures of "Ambiguity aversion" and the psychological scale of "Intolerance to Ambiguity" will be positively correlated: the more "intolerant to ambiguity" the decision makers are, the more they will set high premium for risk with ambiguous probability. 
the results. Section 4 explores economic and psychological explanations of conflict aversion behaviour and concludes.

\section{SURVEY DESIGN}

\subsection{Questionnaire design}

The questionnaire was designed to ask insurers what minimum pure premium ${ }^{2}$ they would charge for a particular risk. The respondents also had the possibility to refuse the insurance demand. The risk contexts were an Earthquake (insuring a factory against a property damage caused by an earthquake) and damage due to pollution (insuring a plant that uses toxic chemicals during the production process), using scenarios that were similar to ones used by Kunreuther et al. (1995) and de Marcellis (2000). Both scenarios involved environmental damages for firms because such damages, contrary to life insurance risks, are in general not perfectly measurable (e.g. lack of data base, scientific controversies...) and thus ambiguous.

Table II outlines the three informational conditions that were introduced. Note that whatever the informational condition, (a) participants received information about the probability of the risk from two independent sources of information; and (b) there was no disagreement or imprecision with respect to the size of the loss which was well specified. In this article, the common "risky" condition is called the Consensual and Precise probability (or Cs-p) case because in that condition two sources of information agree on a precise probabilistic prediction. Compared with this Cs-p condition, the others two conditions are ambiguous: in the Consensual and Imprecise probability condition (called Cs-i), ambiguity comes from imprecision (the probability belongs to a range), whereas in the Conflicting and Precise probability condition (called Cf-p), ambiguity comes from disagreement. Note that generally speaking, conflict "refers to disagreement over states of real reality that cannot hold true simultaneously" 
TABLE II

Presentation of three informational conditions ${ }^{4}$

Unambiguous condition

Ambiguous conditions

\begin{tabular}{|c|c|c|}
\hline $\begin{array}{l}\text { Precise and } \\
\text { Consensual } \\
\text { probability (Cs-p) }\end{array}$ & $\begin{array}{l}\text { Imprecise and } \\
\text { consensual } \\
\text { probability (Cs-i) }\end{array}$ & $\begin{array}{l}\text { Precise and } \\
\text { conflicting } \\
\text { probability (Cf-p) }\end{array}$ \\
\hline $\begin{array}{l}\text { Both sources of } \\
\text { information } \\
\text { agree on the } \\
\text { estimated } \\
\text { probability. The } \\
\text { estimated } \\
\text { probability is precise } \\
\text { (a point estimate) }\end{array}$ & $\begin{array}{l}\text { Both sources of } \\
\text { information } \\
\text { agree on } \\
\text { the estimated } \\
\text { probability. But } \\
\text { the estimated } \\
\text { probability is } \\
\text { imprecise (a range) }\end{array}$ & $\begin{array}{l}\text { Each source of } \\
\text { information } \\
\text { gives a precise } \\
\text { estimate, but } \\
\text { the two } \\
\text { estimates are } \\
\text { different } \\
\text { (disagreement or } \\
\text { conflict on the } \\
\text { probability) }\end{array}$ \\
\hline $\begin{array}{l}\text { Both source A and } \\
\text { source B say } p=2 \%\end{array}$ & $\begin{array}{l}\text { Both source A and } \\
\text { source B say } \\
p \in[1 \% ; 3 \%]\end{array}$ & $\begin{array}{l}\text { Source A says } \\
p_{A}=1 \% \text { while } \\
\text { source B says } \\
p_{B}=2 \%\end{array}$ \\
\hline
\end{tabular}

(Smithson, 1999), but in this study, conflict refers to disagreement over the probabilities of the states (rather than over the list of the states). This is because providing conflicting probability estimates is one of the conventional way to establish ambiguity in the literature (cf. Kunreuther et al., 1995, p. 340; Smithson, 1999; Viscusi and Chesson, 1999, pp. 158159). ${ }^{3}$ Finally, it is noteworthy that in both ambiguous Cs-i and Cf-p conditions, the estimate ranged from $p_{\min }$ to $p_{\max }$ such that the mean value of the range was exactly equal to the probability provided in the unambiguous Cs-p condition.

In the Pollution scenario the loss was 1.5 million $€$, the mean probability was $p=0.002$ and the range was [0.001; 
0.003]. In the Earthquake scenario, the loss was higher (7.5 million $€)$ and the probability larger $(p=2 \%, \mathrm{p} \in[0.01 ; 0.03])$. In both scenarios, the three informational conditions were established exactly as described in Table II. In the Pollution scenario for instance, the information provided in the unambiguous Cs-p condition was the following: "Environmental studies establish with precision that the probability of pollution damage in the firm is $p=0.002$ ". Then, the ambiguity of the situation was manipulated as follows. In the ambiguous Cs-i condition, participants could read: "You have information about the probability of the pollution risk, but you don't know precisely what the probability of the risk is. Some experts of your Technical Department and some independent experts estimate that this probability is imprecise. They agree on the difficulty of giving a precise point estimate. According to those experts, the mean probability of the risk is 0.002. More precisely, they agree on estimating that the probability belongs to the range $p[0.001 ; 0.003]$ ". Finally, in the Cf-p condition, the participants were provided the following information about the probability of the loss: "Experts estimate it is really difficult to set up a precise probability. In your opinion, it seems that $p=0.002$ is a 'good' point estimate of the probability. However, you know that this mean probability covers a wide disagreement. One group of experts estimates that the probability is smaller and proposes $p=0.001$, while the other group of experts estimates that the probability is greater and proposes $p=0.003$ ".

The survey was divided into two parts. In the first part, the participants were presented with six insurance pricing tasks (two scenarios $\times$ three informational conditions). For each risk, the participant's first task was to accept or reject the insurance demand. Then, when the insurance demand was accepted, the second task was to set an insurance premium. The second part of the survey contained several sociodemographic questions (e.g. sex), questions about the job (e.g. job description, past experience in the job...), and a psychological scale measuring intolerance to ambiguity. Questions about the job (e.g. familiarity with the damages described in 
the survey) were used to compute a "familiarity index" and to test prediction 3. Finally, the psychological scale was Budner 16-item "Intolerance of Ambiguity" scale (Budner, 1962). This scale measures person's ability to feel comfortable and accept situations where variables, alternatives, or outcomes are poorly defined or unclear (Budner, 1962). According to Budner (1962), ambiguity intolerant persons are uncomfortable when they face a lack of information (uncertainty) and/or a new, complex or insoluble situation. Ambiguity intolerance is defined as "the tendency to perceive (i.e. interpret) ambiguous situations as sources of threat"and its opposite, ambiguity tolerance, denotes "the tendency to perceive ambiguous situations as desirable" (Budner, 1962, p. 30). Examples of items are for instance: "People who insist upon a yes or no answer just don't know how complicated things really are."(item 16), "An expert who doesn't come up with a definite answer probably doesn't know too much." (item 1). Participants rate each item on a 7-point Likert scale (ranging from 1= "strongly disagree" to $7=$ "strongly agree"), and alternative items have the response scale reversed such that high scores indicate a greater intolerance for ambiguity (a perfectly tolerant person would score 16 and a perfectly intolerant person 112).

\subsection{Sampling plan}

The questionnaire was sent, with the assistance from the 'Institut des Actuaires' (French Institute of Actuaries) to 1300 members. The members of the 'Institut des Actuaires' were all students in Actuary Programs of French Universities (e.g. Euro-Institut d'Actuariat, ENSAE, ISFA). According to the members of the profession, actuaries are "experts who calculate insurance risks and premiums" (IFSA, http://isfa.univlyon1.fr/); they are "expert in evaluating the likelihood of future events, designing creative ways to reduce the likelihood of undesirable events, decreasing the impact of undesirable events that do occur" (American Academy of Actuaries, http://www. beanactuary.org). Actuaries are then definitely experts of insurance. Furthermore, since they have a high training in statistics, 
probability, and economic theory of decision making, they can as well be considered as experts (or "sophisticated participants") of decision making under uncertainty (cf. Shanteau, 1992; Shanteau and Stewart, 1992).

In order to control for potential order effects, two versions (A and $\mathrm{B}$ ) of the questionnaire were sent with a cover letter, that mentioned the support of the Institut des Actuaires and stamped return envelope. Three months later, the French Institut of Actuaries put an advertisement on its web site to invite members who had received the questionnaire to answer. The final sample consisted of 78 questionnaires (a response rate of $6 \%)\left(n_{A}=37, n_{B}=41\right)$. The fact that the exact job of the members of the 'Institut des Actuaires' was not given in the database partly explains the low rate of response (i.e. the mailing reached many members who do not work in the technical department of Insurance CIEs). Furthermore, since about $2 / 3$ of the members are specialized in "life insurance", many members may have thought the questionnaire, which contained scenarios about environmental risks, was too specific. But the survey contained environmental risks because imprecision and conflict surrounding probabilities estimates are much more realistic in the environmental field than in the life-insurance field. A possible sample selection bias is another limitation of the survey, and prevents us from generalizing our results. Actually, since we do not have any statistical data on the whole sample, we cannot compare various descriptive statistics of our whole sample with the subgroup of actuaries who provided answers to our questionnaire. Respondents had an average of 6 years of work experience (from 6 months to 30 years, Median $=4$ years), and a vast majority $(85.9 \%)$ were men (11 women). About $46.15 \%$ of the respondent were specialized in life insurance; $29.5 \%$ in non-life insurance, the remaining $24.5 \%$ had another specialization. About $29.5 \%$ were actuaries or underwriters; $19.2 \%$ worked in the research department of insurance companies; $18 \%$ were consultants, the remaining $33.33 \%$ include respondents who had various jobs in the field of insurance and 
finance (e.g. insurance brokers, finance, managers in insurance companies...).

\section{RESULTS}

\subsection{Descriptive findings}

\subsubsection{Order effect}

In order to control for potential order effects, the order of presentation of the informational contexts was varied and two different questionnaires were sent. A series of $t$-tests for independent samples reveals that the order of presentation does not have any impact on the dependent variables (i.e. the six premiums). Subsequent statistical analyses are thus done on the overall data base.

\subsubsection{Insurance premiums and number of refusals}

Insurers were asked what minimum pure premium they would charge in order to insure the risks described in the scenarios. Following Kunreuther et al. (1995) analysis, the premiums were normalized by expected value (EL), which facilitates comparison across the two scenarios that have different loss and probability levels and across informational contexts. The ratio Premium/EL provides a useful way of determining the impact of the informational context on the prices since it gives a reference point that facilitates the understanding of insurers' behaviour. For instance, a normalized premium of 1.5 indicates that the premium set up is $50 \%$ higher than the expected loss. More interestingly, since the imprecision of the probability was varied using ranges [mean probability $\pm 50 \%$ of the mean probability], a normalized premium of 1 indicates that respondent computed the expected loss with the mean value of the probability range, whereas a normalized premium of 50 (respectively, 1.5) suggests that s/he used the minimum (respectively, maximum) probability of the range. For instance, in the Earthquake scenario, given the amount of 
the loss (7.5 million $€)$ and the probability range [0.01; 0.03 ], the expected loss is equal to $€ 150,000$. A premium computed with $p_{\max }=0.003$ is equal to $€ 225,000$ and the normalized premium 1.5. Table III presents the means for the normalized premiums for the six experimental conditions in the survey. It shows that the mean normalized premium is greater than 1 in all the conditions of both scenarios and that the mean premium increases with the imprecision of the probabilistic information and conflict. Two insurers only gave a premium lower than the expected loss (in the three situations) for the Pollution scenario, but they did not explain their answers. Note that the maximum normalized premium is 6.67 , this is equivalent to a premium of 1 million $€$. Moreover, since the respondents had the possibility of refusing the insurance demand, Table III also shows the number of refusals. The mean rate of

TABLE III

Mean normalized premium, by scenario and informational context

\begin{tabular}{|c|c|c|c|c|}
\hline Scenario & Statistics & Cs-p & Cs-i & Cf-p \\
\hline \multirow[t]{3}{*}{ Pollution } & Mean premium & 1.35 & 1.78 & 1.88 \\
\hline & $\begin{array}{l}\text { [min premium; } \\
\text { max premium] }\end{array}$ & {$[0.65 ; 6.67]$} & {$[0.83 ; 6.67]$} & {$[0.90 ; 6.67]$} \\
\hline & $\begin{array}{l}\text { Number of pre- } \\
\text { mium (refusals) }\end{array}$ & $72(6)$ & $70(8)$ & $64(14)$ \\
\hline \multirow[t]{3}{*}{ Earthquake } & Mean premium & 1.43 & 1.89 & 2.01 \\
\hline & $\begin{array}{l}\text { [min premium; } \\
\text { max premium] }\end{array}$ & {$[0.80 ; 6]$} & {$[1 ; 6.7]$} & {$[1 ; 6.7]$} \\
\hline & $\begin{array}{l}\text { Number of pre- } \\
\text { mium (refusals) }\end{array}$ & $68(10)$ & $65(13)$ & $60(18)$ \\
\hline \multirow{3}{*}{$\begin{array}{l}\text { All } \\
\text { (pollution } \\
+ \text { earthquake) }\end{array}$} & Mean premium & 1.39 & 1.83 & 1.94 \\
\hline & $\begin{array}{l}\text { [min premium; } \\
\text { max premium] }\end{array}$ & {$[0.65 ; 6.67]$} & {$[0.83 ; 6.67]$} & {$[0.90 ; 6.67]$} \\
\hline & $\begin{array}{l}\text { Number of pre- } \\
\text { mium (refusals) }\end{array}$ & $140(16)$ & $135(21)$ & $124(32)$ \\
\hline
\end{tabular}


refusals is greater in the Earthquake scenario (17.5\%) than in the Pollution scenario $(12 \%)$, but in both scenarios, the rate of refusals increases with imprecision and conflict.

\subsubsection{Tolerance of ambiguity}

Budner's (1962) 16-item scale of ambiguity intolerance was used for this study (called TOLAMB). TOLAMB measure of attitude towards ambiguity was used for differentiating respondents with respect to their attitude to ambiguity and for hypotheses testing. In our sample, the reliability alpha of the total scale is 0.41 and tolerance to ambiguity mean value is 50.98 (median value $=52)$. Since high scores $(\max =112$, $\min =16$ ) indicate a greater intolerance to ambiguity this result suggests neutrality towards ambiguity (i.e. respondents were neither tolerant nor intolerant). Gosh and Ray (1997) also obtained a mean value of 50 with the same scale using MBA students.

\subsubsection{Familiarity}

Since all respondents are members of the French Institute of Actuaries, they all have great experience in insurance. However, given the characteristics of the scenarios, some respondents, specialized in non-life insurance and/or on environmental damages, are more familiar than others with the scenarios of the survey. A "familiarity" index was computed in order to take this into account and for hypothesis testing. This index allows us to classify respondents in three categories, given their job characteristics and their answer to a question about their familiarity with the scenarios. Respondents whose job consists in insuring firms against environmental risks are in the "Very familiar" category $(n=7)$, whereas respondents who work in the life insurance branch of their Insurance Company are in the "Not familiar" category $(n=$ $55)$. Finally, the "Familiar" category $(n=16)$ includes respondents who are familiar with firm's risks but not specialized 
in environmental risks. Amongst the 78 respondents, few are specialized in environmental risk, and most of the respondents $(70 \%)$ are specialized in life insurance. This reflects the overall distribution at the national level, since around $2 / 3$ of the actuaries work in the life insurance branch of insurance companies.

\subsection{Testing the ambiguity aversion hypothesis}

In order to look at the impact of the informational context on premiums a three (informational context) $\times$ two (scenario) ANOVA, with repeated measures on the two factors, was performed. ${ }^{5}$ It shows that the scenario does not have any significant main effect ${ }^{6}$ on the normalized premiums, $F(1 ; 53)=$ $1,129, p=0.293$, but reveals a significant main effect of the informational context, $F(1.44 ; 76,29)=45,359, p=0.000$ (with Greenhouse-Geisser adjustment, sphericity is not assumed). The interaction effect is not significant. A series of two by two comparisons (Bonferroni tests) then shows that across scenarios, the mean premiums for Cs-i $(M=1.83)$ and Cf-p $(M=1.94)$ are significantly higher $(p=0.000)$ than the mean premium for Cs-p $(M=1.39)$. This means, that across scenarios, ambiguity aversion is significant. Subsequent statistical analysis performed on each scenario leads to similar results: the effect of the information is significant in Pollution, $F(1,35 ; 81,53)=44,192, p=0.000$ (Greenhouse-Geisser test, sphericity assumed), as well as in Earthquake, $F(2 ; 114)=$ $48,364, p=0.000)$. Moreover, ambiguity aversion is significant in each scenario. Indeed, in Pollution $(\mathrm{P})$, as well as in Earthquake $(\mathrm{E})$, mean premiums under Cs-i $\left(M_{E}=1.89 ; M_{\mathrm{P}}=1.78\right)$ and mean premiums under Cf-p $\left(M_{E}=2.01 ; M_{\mathrm{P}}=1.88\right)$ are significantly higher (at $p<0.000$ level) than mean premiums under Cs-p $\left(M_{\mathrm{E}}=1.43 ; M_{\mathrm{P}}=1.35\right)$. In this population of insurers, ambiguity aversion is then pervasive. This result is consistent with the results of previous survey of insurers (de Marcellis 2000; Kunreuther et al. 1995 ) that indicate insurers behave in an ambiguity-averse way and set up higher premiums under ambiguous risks. 


\subsection{Testing the conflict aversion hypothesis}

As said before, the informational context has a significant main effect on premiums. Testing the "conflict aversion" hypothesis requires to compare the Cf-p premiums with the Cs-i premiums, and a $2 \times 2$ comparison (Bonferroni test) was then performed. It reveals that, across scenarios, the mean premium under Cf-p $(M=1.94)$ is significantly higher $(p=$ $0.047)$ than the mean premium under Cs-i $(M=1.83)$. This means that conflict aversion is pervasive in this population of insurers. Note, however, that this effect is significant at the aggregate level only ( $p=0.301$ in Pollution, and $p=0.82$ in Earthquake). In order to better understand whether different sources of ambiguity have different impacts on insurers' behaviour, another series of statistical tests was performed. This new analysis was based on the premiums of the 53 respondents who did not reject any insurance demand and who provided a premium in each of the three informational context in both scenarios. It confirms that conflict aversion is significant across scenarios $(p=0.047)$. More interestingly, it shows that, on that sub-sample of respondents, conflict aversion becomes significant in the Eartquake scenario $(2 \times 2$ comparison, $p=0.042$, Bonferroni two-tailed test), and tends to be significant in the Pollution scenario $(2 \times 2$ comparison, $p=$ 0.068 , two-tailed test). Finally, and in order to test prediction 3.2 , and to look at impact of the informational context on the numbers of refusals, a Cochran test (the Cochran test is a generalization of McNemar tests for $\mathrm{k}$ matched-samples) was performed. This test reveals that the informational context has a significant impact on the number of refusals in both scenarios (in the Pollution scenario, $Q(2)=11.55, p<0.01$ and in the Earthquake scenario, $Q(2)=8.909, p=0.05)$. However, results of a series of McNemar test $(2 \times 2$ comparisons $)$ show that the number of refusals under Cf-p is not significantly higher than under Cs-i ( $p>0.05$ in both scenarios). Actually, the only significant difference is the difference between the number of refusals in the Cs-p condition and in the Cf-p condition $(p<0.01$ in Pollution and $p<0.05$ in Earthquake), the number 
of refusals in the Cf-p condition being significantly higher than the number of refusals in the Cs-p condition in both scenarios (cf. Table III).

\subsection{Testing P3. The familiarity hypothesis}

In order to test the "familiarity hypothesis", the premiums under Cs-i and Cf-p were normalized by the premiums under Cs-p, and, in each scenario, two ratios: Norm_Csi $=(\mathrm{Cs}-\mathrm{i}$ Premium/Cs-p Premium) and Norm_Cfp $=(\mathrm{Cf}-\mathrm{p}$ Premium/ Cs-p Premium), were computed. These ratios highlight deviations from the Cs-p condition, and give the "size" of the ambiguity aversion: a Norm_Cs-i ratio of 1.2 for instance, means that the premium charge under Cs-i is $20 \%$ higher than the premium set in the Cs-p. In other words, the higher the ratio, the higher the intolerance to ambiguity is. Comparing these ratios across groups of familiarity then allows us to test whether, as the "familiarity hypothesis" says, ambiguity aversion decreases with familiarity. A series of ANOVA, with the four ratios as the dependent variables, and familiarity as the unique between subject factor, was performed. Contrary to what Hypothesis 3 predicts, this analysis reveals that the degree of "familiarity" of the respondent does not have any significant impact on the premiums (see Table IV). However, concerning this hypothesis, the small size of the groups prevents us from a generalization of our results.

\subsection{Testing P4. Intolerance to ambiguity and Ambiguity aversion}

Prediction 4 predicts a positive correlation between the economic measures (cf. the Norm_Csi and Norm_Cfp ratios) and the psychological measure for ambiguity aversion. Since high scores of TOLAMB indicate a greater intolerance to ambiguity, and that higher Norm_Csi and Norm_Cfp scores indicate higher intolerance to ambiguity too, we can predict a positive correlation between the economic measures and the psychological measure. Statistical analysis reveals that, in our 
TABLE IV

Mean premiums (SD) and size of the sample, by familiarity

\begin{tabular}{lllll}
\hline Scenario & Ratio & Not familiar & Familiar & Very familiar \\
\hline \multirow{2}{*}{ Pollution } & \multirow{2}{*}{ Norm_Csi } & $1.35(0.26)$ & $1.35(0.17)$ & $1.30(0.28)$ \\
& & $n=49$ & $n=15$ & $n=6$ \\
& \multirow{2}{*}{ Norm_Cfp } & $1.39(0.38)$ & $1.42(0.24)$ & $1.30(0.23)$ \\
& & $n=44$ & $n=14$ & $n=6$ \\
Earthquake & \multirow{2}{*}{ Norm_Csi } & $1.34(0.27)$ & $1.39(0.31)$ & $1.45(0.51)$ \\
& & $n=42$ & $n=12$ & $n=7$ \\
& \multirow{2}{*}{ Norm_Cfp } & $1.43(0.35)$ & $1.43(0.18)$ & $1.47(0.49)$ \\
& & $n=38$ & $n=12$ & $n=7$ \\
\hline
\end{tabular}

sample, the economic measure and the psychological measure are correlated in one condition only: the Norm_Csi ratio in the Earthquake scenario is significantly and positively correlated with TOLAMB $(r=0.311, p=0.015, n=60)$. But, in the other conditions (Norm_Cfp in Earthquake, Norm_Csi and Norm_Cfp in Pollution), the correlation between the two measures is not at all significant.

\section{DISCUSSION}

Ellsberg noted that ambiguity may come from different sources (e.g. imprecision, conflict). But, apart from Smithson (1999)'s study, experimental studies about attitude towards ambiguity (e.g. Chesson and Viscusi, 2003; Lauriola and Levin, 2001; Maffioletti and Santoni, 2005) have not compared the impact of different sources of ambiguity on behaviours. This article, which presents the results of a survey realized with professional actuaries, is then the first one that tests Smithson's conflict aversion hypothesis and examines the effect of different sources of ambiguity on behaviours (setting of insurance premiums). 
The data show support for the two main hypotheses of the study. First, it confirms previous findings on ambiguity aversion in the insurance field (de Marcellis, 2000; Hogarth and Kunreuther, 1989; Kunreuther et al., 1995) since it shows that the insurers set up higher premiums for ambiguous risks (i.e. Cf-p and Cs-i risks) than for unambiguous risks (i.e. Cs-p risks). Second, the data also support the conflict aversion hypothesis. Indeed, in this survey, the respondents reacted more strongly to conflicting ambiguity than to imprecise ambiguity. This result means that for our professional actuaries, ambiguity coming from conflict was more aversive than ambiguity coming from imprecision.

Given that this survey shows insurance decisions made in the presence of ambiguous risks depend not only on the precision of the probability, but also on the degree of agreement between the sources of information (i.e. consensus), a relevant question concerns the reasons why conflict aversion happens. A first explanation will certainly refer to the variance and will explain that the Cf-p situation is dispreferred because it covers a wider probability range, and is more "uncertain". Suppose for instance, that two sources give you the same imprecise prediction that event $\mathrm{E}$ will occur with probability $p \in[25 \% ; 35 \%]$. You may interpret that prediction as follows: both sources think event $\mathrm{E}$ will occur with probability $30 \%$ and the range is the confidence interval. In the Cf-p situation however, the two experts say it is really difficult to set up a precise probability and one source predicts $p=25 \%$, whereas the other predicts $p=35 \%$. Consequently, you may rationally believe that the probability belongs to a larger range $\left[25 \%-\varepsilon_{i} ; 35 \%+\varepsilon_{l}\right]$ because you can consider that the first (respectively, second) expert believes the probability belong to the range $\left[25 \%-\varepsilon_{i} ; 25 \%+\varepsilon_{j}\right]$ (respectively $\left[30 \%-\varepsilon_{k} ; 30+\varepsilon_{l}\right]$ ). When you frame the situation in that way, the conflicting situation exhibits a "greater volatility" than the imprecise one. If ambiguity aversion is an aversion to variance of the probability, it is obvious that ambiguity averse decision makers are also conflict averse. This variance explanation is interesting, but the results of a series of experiments designed to 
test it (e.g. Becker and Brownson, 1964; Curley and Yates, 1985) do not support it. Furthermore, from a cognitive point of view such a sensitivity to variance is perhaps not realistic. Some psychological studies indeed support the idea that probabilistic judgments are not precise (Budescu and Wallsten, 1995), and this may explain why an increase of $\varepsilon$ may not be sufficient to being perceived. ${ }^{7}$ Consequently, we believe that it is more fruitful to explore the psychological specificities of the Cf-p condition to explain why conflict is avoided. As Viscusi and Chesson (1999) noticed "the agreement between the experts suggests more confidence in the risk estimate". Smithson (1999) precisely tested the hypothesis that conflict affects the perceived credibility of the sources of information more strongly than imprecision, and he found strong support for this cognitive explanation. Attribution theory, which is concerned with the attempts of decision makers to explain (find the causes) of the situations they face (see Hilton et al., 1995) is also particularly relevant to the study of attitudes towards ambiguity. Indeed, since causal explanations involve giving an explanation for why an event has occurred, and mark DM's attempt to better understand a situation (through the attribution of causes to effects), they are likely to be produced in face of uncertainty. Cabantous et al. (2004) precisely develop an attributional explanation for attitude towards ambiguity. Their framework suggests that ambiguity aversion and conflict aversion are the consequence of social perception which favours precision and consensus, especially when the sources of information are experts (Shanteau, 2001), and it also supports the idea that different sources of ambiguity generate different patterns of causal attributions.

In spite of some limitations and its exploratory nature (e.g. small number of valid answers), this survey thus provides clear evidences concerning the way real decision-makers react to different sources of ambiguity. It clearly shows that scientific controversies (i.e. conflict between experts), such as the ones relative to global warming or the so-called "mad cow disease" crisis, can have effective consequences in the market place, and larger economic impacts than scientific 
imprecision. This article also presents some rationales for conflict aversion, and suggests to pursue the study of the attitude towards different sources of ambiguity so as to gain more insight into the type of reasoning used by individuals faced with imprecise probabilities and conflicting estimates of risks.

\section{ACKNOWLEDGEMENTS}

I wish to thank H. Kunreuther, D. Hilton and Ch. Gollier for their extremely helpful comments and suggestions. I acknowledge the support of the French Federation of Insurance Companies, and the financial support of the University of Toulouse (Université Toulouse 1).

\section{NOTES}

1. Budescu and Wallsten (1995) argue that economic studies about "ambiguity aversion" have not studied behaviour under ambiguity (in its usual and linguistic meaning) but behaviour under imprecise probabilities. We agree with this remark but we still use the word ambiguity in its "Ellsbergian" meaning i.e. ambiguity is "uncertainty about the probability" and following Ellsberg, we consider that there is ambiguity when the information is "scanty or obviously unreliable or highly conflicting" or "when there are questions of reliability and relevance of information, and particularly where there is conflicting opinion and evidence" (Ellsberg, 1961, p. 659).

2. Pure premium is the actuarial value i.e. it is the expected loss.

3. Note that since the Cf-p conditions in this study are potentially "low" conflict situations, this means that using another kind of conflict (e.g. "About half the experts say studies show that there is a link between aluminium and Alzheimer's disease, while the other half say studies do not show there is such a link", Smithson, 1999), could only increase the feeling of conflict, and then conflict aversion.

4. The French version of the questionnaire can be downloaded on my website: http://www.l.cabantous.freeuk.com/

5. Kunreuther et al. (1995) employed the $\log$ (Premium/Expected value) because the distribution of the premium was highly skewed. Such a transformation was performed on our data that gave very similar results to the ones reported in the article. 
6. The main effect of a variable would be whether there was an effect of that variable, collapsing across levels of the other variables.

7. Two recent articles however found that decision makers are sensitive to the range of probability ( $\mathrm{Du}$ and Budescu, 2005; Maffioletti and Santoni, 2005). In these articles, however, the difference between two range is larger than $\varepsilon$.

\section{REFERENCES}

Becker, S. and Brownson, F. (1964), What price ambiguity? or the role of ambiguity in decision-making, The Journal of Political Economy 72, 2-73.

Budescu, D., Kuhn, K., Kramer, K. and Johnson, T. (2002), Modeling certainty equivalents for imprecise gambles, Organizational Behavior and Human Decision Processes 88, 748-768.

Budescu, D. and Wallsten, T. (1995), Processing linguistic probabilities: general principles and empirical evidence. In Busemeyer J., Hastie R. and Medin D.L. (eds.), Decision Making from a Cognitive Perspective. San Diego: Academic Press, pp. 275-318.

Budner, S. (1962), Intolerance of ambiguity as a personality variable, Journal of Personality 30, 29-50.

Cabantous, L., Hilton D. and Shanteau, J. (2004), Ambiguity and conflict aversion: an attributional explanation for confidence in one's judgment. Paper presented at the annual conference of the Society for Judgement and Decision Making (SJDM), Minneapolis, US, November 19-22.

Camerer, C. and Weber, M. (1992), Recent developments in modelling preferences: uncertainty and ambiguity, Journal of Risk and Uncertainty 5, 325-370.

Chesson, H. and Viscusi, W.K. (2003), Commonalities in time and ambiguity aversion for long-term risks, Theory and Decision 54, 57-71.

Cohen, M., Jaffray, J.-Y. and Said, T. (1985), Individual behavior under risk and uncertainty: an experimental study, Theory and Decision 18, 203-228.

Cohen, M., Jaffray, J.-Y. and Said, T. (1987), Experimental comparison of individual behavior under risk and under uncertainty for gains and for losses, Organizational Behavior and Human Decision Processes 39(1), $1-22$.

Curley, S. and Yates, F. (1985), The center and range of the probability interval as factors affecting ambiguity preferences, Organizational Behavior and Human Decision Processes 36, 272-287.

de Marcellis, N. (2000), Aux frontières de l'assurabilité des risques de l'entreprise, une analyse expérimentale des décisions de l'assureur. Thèse de doctorat en gestion. 
Du, N. and Budescu, D. (2005), The effects of imprecise probabilities and outcomes in evaluating investment option, Management Science, 51(12), 1791-1803.

Ellsberg, D. (1961), Risk, ambiguity and the Savage axioms, The Quarterly Journal of Economics 75, 643-669.

Fox, G. and Tversky, A. (1995), Ambiguity aversion and comparative ignorance, The Quarterly Journal of Economics 110, 585-603.

Fox, G. and Weber, M. (2002), Ambiguity aversion, comparative ignorance and decision context, Organizational Behavior and Human and Decision Processes 88(1), 476-498.

Gosh, D. and Ray, M. (1992), Risk attitude, ambiguity intolerance and decision making: an exploratory investigation, Decision Science 23(2), 431-444.

Gosh, D. and Ray, M. (1997), Risk, ambiguity and decision choice: some additional evidences, Decision Science 28(1), 81-104.

Heath, C. and Tversky, A. (1991), Preference and belief: ambiguity and competence in choice under uncertainty, The Journal of Risk and Uncertainty 4, 5-28.

Hilton, D.J., Smith, R.H. and Kim S.-H. (1995), Processes of causal explanation and dispositional attribution, Journal of Personality and Social Psychology 68(3), 377-387.

Ho, J., Keller, L. and Keltyka, P. (2002), Effects of outcome and probabilistic ambiguity on managerial choices, The Journal of Risk and Uncertainty 24(1), 47-74.

Hogarth, R. and Kunreuther, H. (1989), Risk, ambiguity and insurance, Journal of Risk and Uncertainty 2, 5-35.

Kunreuther, H., Meszaros, J. Hogarth, R. and Spranca, M. (1995), Ambiguity and underwriter decision processes, Journal of Economic Behavior and Organization 26, 337-352.

Lauriola, M. and Levin, I. (2001), Relating individual differences in attitude toward ambiguity to risky choice, Journal of Behavioral Decision Making 14, 107-122.

Maffioletti, A. and Santoni, M. (2005), Do trade union leaders violate subjective expected utility? some insights from experimental data, Theory and Decision 59(3), 207-253.

Savage, L. (1954), The Foundations of Statistics. New York: Wiley.

Sherman, R. (1974), The psychological difference between ambiguity and risk, Quarterly Journal of Economics 88, 166-169.

Shanteau, J. (1992), Competence in experts: the role of task characteristics, Organizational Behavior and Human Decision Processes, 53(2), 252-266 (Special issue on Experts and Expert Systems).

Shanteau, J. (2001), What does it mean when expert disagree? In Salas, E. and Klein, G. (eds.), Linking Expertise and Naturalistic Decision Making. NJ: Erlbaum. 
Shanteau, J., and Stewart, T.R. (1992), Why study expert decision making? Some historical perspectives and comments. Organizational Behavior and Human Decision Processes 53(2), 95-106 (Special issue on Experts and Expert Systems).

Smithson, M. (1999), Conflict aversion: preference for ambiguity vs conflict in sources and evidence, Organizational Behavior and Human Decision Processes 79(3), 179-198.

Taylor, K. (1995), Testing credit and blame attributions as explanation for choices under ambiguity, Organizational Behavior and Human Decision Processes 64(2), 128-137.

Viscusi, K. and Chesson, H. (1999), Hopes and fears: the conflicting effects of risk ambiguity, Theory and Decision 47, 153-178.

Address for correspondence: Laure Cabantous, Leeds University Business School, Leeds University, LS2 9JT Leeds, UK. Phone: +44-115-9482713 E-mail: 1c@lubs.leeds.ac.uk or 1.cabantous@freeuk.com 